\title{
LOS MEDIOS DE COMUNICACIÓN COMUNITARIOS,
}

\author{
ALTERNATIVOS Y POPULARES, Y LA EXPERIENCIA \\ DE JÓVENES DE SECTORES POBRES URBANOS \\ -Paraná, Argentina-
}

\section{Community, Alternative and Popular Media, AND THE EXPERIENCE OF PoOr URban Youth -Paraná, Argentina-}

Lucía Marioni*

Resumen: En este trabajo nos proponemos reflexionar sobre la inserción de jóvenes pobres urbanos de la ciudad de Paraná - Entre Ríos, Argentina — en prácticas mediáticas — radiofónicas, gráficas y audiovisuales- de comunicación comunitaria, alternativa y popular. Particularmente, exploramos sus diferentes vivencias, buscando aproximarnos a las significaciones producidas por este grupo en torno a ellas.

Este artículo se enmarca en una investigación doctoral en curso acerca de la experiencia de jóvenes de sectores pobres urbanos en organizaciones e instituciones que trabajan para su inclusión social desde propuestas de espacios culturales comunicacionales. Presentamos una somera contextualización, un mapeo de medios en la provincia y un análisis a partir de entrevistas y observación participante, los cuales constituyen el marco interpretativo que orienta nuestra investigación.

\footnotetext{
* Licenciada en Comunicación Social, doctoranda en Ciencias Sociales. Centro de Investigaciones Científicas y Técnicas de Entre Ríos, Consejo Nacional de Investigaciones Científicas y Técnicas, Argentina. Temas de interés: juventudes y participación social y política, http://orcid. org/ 0000-0001-5610-9011, correo e.: marionilucia@gmail.com

Fecha de recepción: 2303 18; Fecha de aceptación: 171118.
}

(cc) EY-NC-ND Páginas 229-256. 
Palabras clave: juventudes, participación, comunicación comunitaria, inclusión social.

Abstract: In this paper we reflect on the insertion of poor urban youth from the city of Paraná - Entre Ríos, Argentina - into media practices — radio, graphic and audiovisual — of community, alternative and popular communication. In particular, we explore their different experiences, approaching the meanings of practices produced by this group.

This article is part of a doctoral research about the experience of young people from poor urban sectors in organizations and institutions that work for their social inclusion through cultural projects. We present a brief contextualization, a mapping of media in the province and an analysis based on interviews and participant observation, which constitute the interpretive framework that guides our investigation.

Keywords: youth, participation, community communication, social inclusión.

\section{Introducción}

Las tendencias económico-sociales y políticas recientes en Argentina y América Latina han profundizado procesos de vulneración y exclusión social de grandes sectores de la población en un escenario de crisis que, a la vez que integra el recurrente ciclo capitalista que periódicamente desemboca en una caída drástica en todos los órdenes de la vida económica, es parte de un quiebre civilizatorio de carácter integral que incluye factores ambientales, climáticos, energéticos, hídricos y alimenticios (Vega Cantor, 2009). Esta crisis, que aparece en múltiples dimensiones, se manifiesta con fuerza como crisis de la sociedad salarial.

En este contexto, las formas de organización de lo social y la po- 
lítica también vienen atravesando transformaciones, produciéndose lo que para el caso de Argentina algunos autores definen como territorialización de la política y politización de los espacios de la vida cotidiana y los territorios (Merklen, 2005; Svampa, 2005; Vommaro, 2015). Al decir de Vommaro, en las últimas décadas "se desplegó un doble proceso de surgimiento y expansión de las organizaciones sociales, a la vez que de ampliación de las formas y espacios de expresión de la política" (Vommaro, 2012: 63). Prácticas de organización social de base territorial e insertas en redes comunitarias desarrollan actividades y construyen espacios colectivos en torno a la asistencia de necesidades básicas insatisfechas, el trabajo, expresiones culturales y la elaboración de proyectos de organización política.

Entre los repertorios de acción desplegados por estas organizACIONES HA IDO ASUMiendo relevancia la creación y sostenimiento de medios de comunicación propios. Radios, canales, revistas, boletines y plataformas multimedia insertos en organizaciones territoriales, centros culturales, asociaciones civiles, vecinales, organizaciones no gubernamentales, agrupaciones políticas. Se trata de experiencias mediáticas de comunicación con diferentes características y modos de nombrarse a sí mismas, algunas como comunitarias, otras como alternativas, varias como populares. No obstante, todas ellas comparten una capacidad: la de ser alterativas al orden político existente o respecto del sujeto de comunicación (Fasano, 2015).

Reivindicadas desde hace más de tres décadas en Argentina como espacios autogestionados para la confrontación del discurso hegemónico de los medios masivos y la participación en instancias de construcción política alternativa (Lamas y Lewin, 1995), estas experiencias tienen diferente desarrollo en los distintos territorios de nuestro país, y mayor presencia en los centros urbanos más grandes. En general, son medios que se han identificado como proyectos para la construcción democrática y de ciudadanía, y con ello han puesto énfasis en cuestiones como la legitimación de las voces de los sectores tradicionalmente marginados y excluidos, la visibilización de sus necesidades y la construcción de demandas y reivindicaciones políticas, sociales, económicas y culturales en términos de derechos (Kejval, 
2013).

$\mathrm{Al}$ respecto, publicaciones académicas ${ }^{1} \mathrm{y}$ de redes de medios ${ }^{2}$ han destacado el lugar que estos medios han promovido para las juventudes, grupo poblacional con afecciones específicas en los procesos de vulneración y marginación (Fernández y López, 2005). Destacan Cabral y Jaime (s.f.) en un encuentro sobre juventudes del Foro Argentino de Radios Comunitarias, Farco, que estos medios "asumieron - no sin contradicciones - un rol similar al de muchas otras organizaciones sociales y comunitarias: ser espacios de recepción de las problemáticas de los jóvenes".

En este trabajo nos proponemos aproximarnos a comprender cómo es la inserción de las juventudes de sectores pobres urbanos de la ciudad de Paraná, provincia de Entre Ríos, en prácticas mediáticas de comunicación comunitaria, alternativa y popular. Esta ciudad, junto con Concordia, concentran la mayor población de la provincia así como también los índices más altos de pobreza. En Paraná se encuentra la mayor cantidad de prácticas mediáticas de comunicación comunitaria, alternativa y popular, lugar de este estudio.

Realizamos un revelamiento y caracterización de los medios en la provincia y una aproximación a cuatro medios en la ciudad: dos radiofónicos y dos gráficos — modalidades mayoritarias entre los reveladoscon el objeto de acercarnos a la comprensión de la experiencia de las y los jóvenes en torno a ellos y recuperar significaciones construidas. Lo hacemos especialmente desde la observación participante realizada en las organizaciones y entrevistas a nueve integrantes de las experiencias, ${ }^{3}$ se añade también la búsqueda de información documental.

Compartimos, por un lado, una referencia a la relación entre las juventudes y la pobreza urbana en el país y la provincia y una contextualización a las prácticas mediáticas de comunicación comunitaria, alternativa y popular; para luego compartir los resultados del revelamiento y la identificación de diferentes "tipos" en la participación de las y los jóvenes. Finalmente, realizamos una aproximación a las diferentes

\footnotetext{
${ }^{1}$ Mata (1998, 2002), Cabral (2004), Cabral y Jaime (s.f.), entre otros.

${ }^{2}$ AMARC-ALER (2004), por ejemplo.

${ }^{3}$ Reemplazamos los nombres por seudónimos por decisión de los entrevistados. Esto permite también jerarquizar los procesos de significación más que los actores particulares.
} 
experiencias juveniles en las prácticas y espacios que se configuran en torno a estos medios en Paraná; a partir de preguntas acerca de qué hacen las y los jóvenes pobres urbanos en estos espacios, cuáles son sus prácticas en ellos, cómo las definen, y cómo se relacionan con los otros actores y las organizaciones.

\section{Las juventudes y la pobreza urbana}

En Argentina, la pobreza en su dimensión urbana es un fenómeno en sí mismo y, en rasgos generales, es estudiada en mayor medida que la pobreza rural. ${ }^{4}$ Se relaciona particularmente con dos elementos: las migraciones desde el espacio rural al urbano en los periodos anteriores, en vínculo con el rol que cumple la economía agropecuaria en el país y la crisis de la sociedad salarial agudizada en diferentes momentos luego de la culminación del sistema de industrialización por sustitución de importaciones (Lattes, 1995; Altimir y Beccaría, 1998; Kessler y Di Virgilio, 2008).

Según información correspondiente al primer semestre de 2017 de la Encuesta Permanente de Hogares, EPH, en Argentina - con una población urbana de $91 \% 5$ - el porcentaje de personas pobres en el espacio urbano asciende a $28.6 \%$, y el de personas indigentes a $6.2 \%$. $^{6}$ Para el caso de Entre Ríos, su población urbana asciende a $85.7 \%$. Paraná y Concordia son las ciudades intermedias que concentran mayor población y que en periodos previos incrementaron tanto su población relativa como los índices de pobreza (Mingo y otros, 2006), son también las que presentan los más altos índices de pobreza. Paraná, con 247,863 habitantes, ${ }^{7}$ es la ciudad con mayor población de la provincia. Le sigue Concordia con 149,450 habitantes. El gran Paraná cuenta con $24.4 \%$ de personas pobres y $4.8 \%$ de personas indigentes. Por su parte, Concordia tiene $42 \%$ de personas pobres y $7,8 \%$ de personas

\footnotetext{
${ }^{4}$ Tanto la Encuesta Permanente de Hogares, EPH, del Instituto Nacional de Estadísticas y Censos, Indec, como algunos informes del Observatorio de la Deuda Social, de la Universidad Católica Argentina, hacen sus mediciones sobre la población urbana.

${ }^{5}$ Según el último censo de población (DGEC, 2010).

${ }^{6}$ Por su parte, el último informe anual del Observatorio de la Deuda Social Argentina, ODSA (2017), de la Universidad Católica Argentina sostiene que 31,4\% de la población es pobre y $5,9 \%$ indigente.

${ }^{7}$ Según el último censo de población (DGEC, 2010).
} 
indigentes (Indec, 2017).

Dentro de los estudios sobre la pobreza, los niños y jóvenes asumen un protagonismo que ha llevado a algunos trabajos sobre estructuras sociales a referirlo como una infantilización y juvenilización de la pobreza. Según estimaciones del Observatorio de la Deuda Social Argentina (2017), en 2016 la propensión a la pobreza absoluta por ingresos alcanzó a 49\% de niños menores de 14 años y $38 \%$ de la población joven - de entre 15 y 29 ańos-, siendo alrededor de $28 \%$ y $11 \%$ para los adultos y adultos mayores, respectivamente. Asimismo, 11\% de los nińos reside en hogares por debajo de la línea de indigencia, mientras que dicho rubro es de aproximadamente $9 \%$ en la población joven, y de 5\% y $1 \%$ entre los adultos y adultos mayores, respectivamente.

Según los resultados de la Encuesta Nacional de Jóvenes realizada en 2014 , en Argentina más de $20 \%$ de los y las jóvenes ${ }^{8}$ se encuentra fuera del mercado laboral y del sistema educativo (Indec, 2014), caracterizados éstos como los dos principales ámbitos de inclusión social para este grupo. La encuesta refiere a ellos como "jóvenes que no estudian y no trabajan ni buscan trabajo", y los halla en "hogares con ingresos bajos" y algunos ocupando su tiempo en "tareas de cuidado": poco menos de la mitad de ellos cuida a niños o personas mayores. La conceptualización como "jóvenes ni-ni-ni” que se construye a partir de la clasificación que realiza la encuesta, además de invisibilizar el trabajo doméstico y de cuidado como tal, conlleva lo que Feijoó (2015) llama "visión mitológica" de las juventudes por incluir dos implícitos: por un lado, que se es ni-ni por la voluntad de serlo; por otro, que tal grupo tiende a incurrir en conductas delictivas.

Un análisis aparte requieren las representaciones que encarnan las y los jóvenes de sectores populares empobrecidos, quienes suelen conformarse en objeto de políticas sociales residuales para el Estado y en jóvenes potencialmente peligrosos, sin futuro y apáticos para el discurso hegemónico de los medios masivos de comunicación (Cubides Martínez, 2016). Este estereotipo así construido ha sido trabajado extensamente por juvenólogos como Saintut (2013), Chaves (2005, 2017), entre otros. En pocas palabras, Chaves explica:

\footnotetext{
${ }^{8}$ Definidos por Indec como la población de entre 15 y 29 años.
} 
Podríamos decir que en una veta conservadora de la sociedad se siguen construyendo dicotómicamente dos grandes tipos de representaciones sobre jóvenes. Por un lado, la imagen del joven integrado, con una representación de moratoria social ligada a las experiencias de vida de clase alta y media alta. Y, en el caso de nuestro país, también de lo que algunos llaman la "clase media media", sostenido en el ideario casi mítico de inclusión de la movilidad social ascendente. El sentido de pertenencia que daba, en un momento de nuestra historia, la inclusión de grandes sectores de la población —a través del puesto de trabajo y la condición de trabajador - a los derechos sociales. Ahí tenemos una imagen en la que se inscriben muchas experiencias juveniles, pero sobre todo funciona como el parámetro a partir del cual se evalúan, muchas veces en términos morales, las prácticas y las experiencias de los jóvenes. Y, por otro lado entonces, la representación del joven "excluido", ya sea como joven peligroso o joven víctima. En general ligado a las experiencias de vida de sectores de clases bajas (Chaves, 2017: 2).

Con ello, los jóvenes pobres urbanos suelen conjugar, junto con su inclusión parcial o exclusión al mercado laboral y al sistema educativo, representaciones heterónomas sobre sí que conforman el segundo implícito de la visión mitológica que plantea Feijoó (2015).

\section{Los medios de comunicación comunitarios, alternativos y populares en Argentina}

Vastos estudios en comunicación han profundizado en los debates acerca de los perfiles comunitario, alternativo y popular de los medios de comunicación (Mata, 1993, 2002, 2006; Krohling Perusso, 1998, 2008; Alfaro, 2000; Kejval, 2009, 2013; Gerbaldo, 2010), produciendo reflexiones diversas acerca de experiencias mediáticas de sectores populares y organizaciones sociales. Sin detenernos en aspectos que escapan a las posibilidades de este trabajo, podemos referir someramente que las diferencias de denominación han sido relacionadas en estos estudios, entre otras cuestiones, con distintos periodos políticos y sociales del país y Latinoamérica. 
Así, la comunicación alternativa es caracterizada como la "otra comunicación” dispuesta a compensar la concentración mediática y a materializar la consigna "Voces múltiples, un solo mundo" que recuperaba el mítico Informe Mc. Bride (1980) de los debates setentistas por un Nuevo Orden Mundial de la Información y Comunicación, NOMIC. La comunicación popular, por su parte, también participa de un clima de época: es construida por las diferentes experiencias así como en los estudios comunicacionales de los años 80 como la "verdadera" comunicación sustancialmente asociada a un proyecto alternativo de sociedad (Festa y otros, 1986) y a los sectores populares, en tanto comunicación "liberadora, transformadora, que tiene al pueblo como generador y protagonista” (Kaplún, 1985: 7); poniendo gran énfasis en los procesos que posibilita (ídem: 1985). Finalmente, la comunicación comunitaria ha ocupado la atención principalmente en la década de los 90 y ha sido fundamentalmente asociada a procesos micro sociales, a debates en torno a la construcción y fortalecimiento de la ciudadanía (Mata, 2002), ubicando la atención en los procesos de significación en los espacios de sociabilidad cotidiana de las comunidades de los sectores populares, espacios que Fasano $(1993,2001)$ ha caracterizado como "comunitarios de significación".

Sin embargo, estas conceptualizaciones no pretenden ni pueden definir de modo acabado las diversas experiencias existentes. Los medios son denominados por sus referentes de uno $\mathrm{u}$ otro modo incorporando y entrelazando diferentes características de las improntas recién comentadas. A los efectos de este trabajo, interesan todas las experiencias identificadas indistintamente por cualquiera de las tres adjetivaciones, debido a que en ellas nos importan los procesos de significación micro sociales construidos y las relaciones comunitarias que en todas ellas se despliegan.

Este tipo de medios tuvieron diferentes momentos de surgimiento y desarrollo en Argentina, principalmente desde la restitución democrática en la década de 1980 hasta la actualidad, poniendo en algunos casos el acento en la democratización de las comunicaciones para la democratización de la sociedad, en otros en la denuncia de 
situaciones de marginalidad y pobreza vividas por grandes grupos sociales, en la oposición a políticas de racionalidad neoliberal de la década de 1990, en el acompañamiento de proyectos de organizaciones territoriales, políticos y culturales, entre otros. Comenzada la mitad de la década de 1990, parte de estos medios comenzaron a consolidar redes y construir espacios de encuentro. En 2001, "estallada" la crisis económica e institucional, las prácticas mediáticas alternativas, comunitarias y populares adquirieron un mayor protagonismo, volviéndose los principales repertorios de acción de diferentes y numerosos colectivos de la sociedad civil. En ese recorrido podemos ubicar a la Red Nacional de Medios Alternativos, RNMA, la Red Indymedia, y el Foro Argentino de Radios Comunitarias, Farco, que asumen lugares relevantes y resignifican esfuerzos de espacios de encuentro anteriores, posicionándose fuertemente en el escenario político social.

El Foro Argentino de Radios Comunitarias, organización que actualmente agrupa 91 radios comunitarias del territorio nacional, reconoce como antecedente a la Asociación de Radios Comunitarias, una organización que reunía alrededor de 20 emisoras, mayoritariamente ubicadas en la Capital Federal en ese entonces, creada en 1988 en defensa de los derechos de sus asociados a ejercer la radiodifusión y trabajar dentro del marco legal, para lo cual era indispensable promover un cambio en la legislación en curso. En la década de 1990 esa asociación se conformó como Federación, y en 2000 se resignificó como Foro, adquiriendo estructura jurídica.

La Red Nacional de Medios Alternativos, RNMA, y la red Indymedia reconocen sus orígenes puntualmente en los sucesos de diciembre de 2001. ${ }^{9}$ La primera, conformada inicialmente como Foro de Medios Alternativos, Fodema, nació luego de una reunión de comunicadores y medios que habían cubierto los episodios de diciembre y que se proponían la conformación de "un espacio social y político para el debate y la acción” (Mesa Suárez, 2014). La segunda, creada a nivel internacional en 1999 durante las manifestaciones contra la cumbre

\footnotetext{
${ }^{9}$ Cuando se dio un estallido social — revueltas en diferentes ciudades del país - en respuesta a la crisis social, económica e institucional de ese tiempo, que generó la renuncia del entonces presidente Fernando de la Rúa.
} 
de la Organización Mundial de Comercio en Seattle, comenzó a organizarse en Argentina también en 2001 cuando inauguró su primer sitio web de publicación abierta y democrática que buscaba volver visible el estallido social y las necesidades de grandes grupos de población en el contexto de crisis. Actualmente, ambas tienen presencia en gran parte del territorio nacional y han contribuido a la formación de vastos colectivos en comunicación popular y alternativa y en acceso libre.

Farco conformó, junto con otros actores individuales y colectivos, la Coalición por una Comunicación Democrática, que en agosto de 2004 tuvo su primera intervención pública con la presentación de los “21 Puntos por una Radiodifusión Democrática”. Ese manifiesto proponía ejes clave para una nueva ley de comunicaciones que reemplazara la que regía para la radiodifusión desde el gobierno de facto de 1976-1983. Declaraba la comunicación como un bien público indispensable en la democratización de la sociedad y derecho fundamental e irrenunciable, y reclamaba la formulación de un nuevo régimen normativo no mercadocéntrico. Se constituyó como un espacio multiorganizacional donde convergieron referentes de organismos de derechos humanos, así como de radios comunitarias y cooperativas - Farco, la Asociación Mundial de Radios Comunitarias, el Instituto Movilizador de Fondos Cooperativos y la Asociación Mundial de Comunicadores Cristianos-, también trabajadores de la comunicación agrupados en la Confederación Sindical de Trabajadores de los Medios de Comunicación Social de la República Argentina, intelectuales, juristas y académicos especialistas en el tema, funcionarios de áreas gubernamentales como Telenoticiosa Americana, Télam; Comité Federal de Radiodifusión, Comfer; Radio Nacional; la Asociación Radios de Universidades Nacionales y organizaciones políticas y territoriales. Tuvo, finalmente, una participación activa en la formulación de la Ley de Servicios de Comunicación Audiovisual N²6,522, Lesca, promulgada en 2009.

La Red Nacional de Medios Alternativos, RNMA, tuvo una posición crítica a la Ley anterior. También exigió desde sus inicios la derogación de la Ley $\mathrm{N}^{\circ}$ 22,285 de Radiodifusión de 1980 y articuló campañas contra el decomiso de equipos. Sin embargo, no formó parte de la Coalición por una Comunicación Democrática y realizó 
consideraciones al proyecto de ley como la no diferenciación de medios de gestión privada sin fines de lucro de los medios comunitarios, alternativos y populares. Asimismo exigió mayor pluralidad y representatividad en los órganos de control y reducción de licencias por prestador. Finalmente, en agosto de 2010 impulsó la creación de la Coordinadora en Defensa de la Comunicación Comunitaria, Alternativa y Popular, CoorDeCCAP, que en su accionar cuenta con denuncias por irregularidades en el otorgamiento de licencias en el marco de la nueva ley, falta de reglamentación específica para la misma así como de un plan técnico (RNMA, 2009).

En los años siguientes surgieron otras redes. Entre ellas la Asociación Argentina de Teledifusoras Pyme y Comunitarias, Aateco, “integrada por más de 200 canales de televisión abierta por aire, de baja y media potencia, surgidos en Argentina una vez finalizada la última dictadura militar"; compartiendo el objetivo de "bregar por otro tipo de comunicación: participativa y democrática” (Aateco, s.f.). Y la Asociación de Revistas Culturales Independientes, Arecia, que en mayo de 2013 adquirió su mayor visibilidad con la presentación de un proyecto de ley de promoción y regulación de los medios gráficos, con la impronta de la Ley de Servicios de Comunicación Audiovisual, LSCA, relacionada con la idea de democratización de las comunicaciones, la necesidad de construir horizontes comunes y la oposición radical al neoliberalismo en términos económicos, sociales, políticos y culturales.

Si bien no es objeto de este trabajo realizar una historia de los medios comunitarios, alternativos y populares en el país, es importante destacar que luego de atravesar un periodo en que las políticas nacionales de comunicación fomentaron su desarrollo y aportaron a su legitimación dentro del orden jurídico durante el gobierno de Cristina Fernandez de Kirchner, 2007-2015, en diciembre de 2015 se inauguró otro vinculado a su desestabilización: al asumir el gobierno nacional, Mauricio Macri modificó LSCA con un decreto de necesidad y urgencia, N²67/2015, y eliminó el organismo esencial para su aplicación: La Agencia Federal de Servicios de Comunicación Audiovisual. Los medios comunitarios, alternativos y populares comenzaron, entonces, un nuevo periodo de lucha por el reconocimiento y sostenibilidad. 


\section{Los medios comunitarios, alternativos y populares en Entre Ríos}

En la provincia, el desarrollo de la comunicación alternativa, popular y comunitaria es tardío respecto al país. Recién iniciada la década de 2000 comienzan a surgir la mayor parte de los medios, momento histórico recesivo y de crisis institucional a nivel nacional así como también de fortalecimiento de las tres primeras redes mencionadas.

A partir de información proveniente de ellas, así como también de las actas de las audiencias públicas regionales de la Defensoría del Público, ${ }^{10}$ pudimos identificar veinte medios definidos como comunitarios, alternativos o populares en la provincia de Entre Ríos (ver figura en página siguiente).

En general, todos se encuentran insertos en organizaciones sociales: organizaciones territoriales, religiosas, vecinales, cooperativas, asociaciones civiles.

Quince de ellos, 75\%, tienen lugar en las ciudades de Paraná y Concordia, que como mencionamos anteriormente son los dos aglomerados urbanos más importantes de la provincia y concentran los mayores índices de pobreza e indigencia. A diferencia de lo que sucede en otras regiones del país, en Entre Ríos estos medios surgen recién a partir de la década del año 2000 y no desde los años 80. Una excepción es la Radio Comunitaria Dońa Munda, referenciada con ese nombre desde 1998 aunque con una historia anterior como pequeña radio comercial. En todos los casos, los perfiles editoriales se han conformado como visibilizadores de las problemáticas sociales.

En general, hacen foco en problemáticas vinculadas a la exclusión y marginalidad, con ello hacen propia la consigna de la inclusión social, algunos más directamente que otros, y varios tienen amplia participación de las comunidades donde se encuentran.

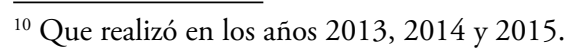


Figura 1. Medios comunitarios, alternativos y populares en Entre Ríos.

\begin{tabular}{|c|c|c|}
\hline Nombre & Ciudad & Surgimiento \\
\hline \multicolumn{3}{|c|}{ medios radiofónicos } \\
\hline Radio Comunitaria Doña Munda & Paraná & 1998 \\
\hline Los pájaros en el río / Pájaros de dignidad & Paraná & 2002 \\
\hline \multirow[t]{2}{*}{ Radio Cualquiera } & Paraná & 2003 \\
\hline & Colonia Avellaneda & 2007 \\
\hline Tizas Rebeldes & Paraná & 2009 \\
\hline Estirpe Entrerriana & María Grande & 2009 \\
\hline Radio Barriletes & Paraná & 2010 \\
\hline Radio Chaná & Victoria & 2010 \\
\hline Radio Chamuyo & Paraná & 2010 \\
\hline Radio Sapukay & Colón & 2014 \\
\hline Cabayú Cuatiá & La Paz & 2014 \\
\hline \multicolumn{3}{|c|}{ medios gráficos } \\
\hline Revista Barriletes & Paraná & 2001 \\
\hline Revista Boca a Boca & Paraná & 2004 \\
\hline La chancleta & Paraná & 2004 \\
\hline El Colectivo & Concordia & 2005 \\
\hline Panza Verde & Concordia & 2005 \\
\hline El Colectivo & Paraná & 2005 \\
\hline Revista Menos que Cero & Concordia & 2009 \\
\hline \multicolumn{3}{|c|}{ medios audiovisuales } \\
\hline Chaski tv & Paraná & 2002 \\
\hline Producciones Sur del Sur & Paraná/Concordia & 2002 \\
\hline
\end{tabular}

Fuente: Elaboración propia a partir de información documental

Por ejemplo, la Asociación Civil Barriletes, que lleva adelante una publicación de calle desde 2001 y una radio comunitaria desde 2009, presenta sus propósitos como:

una oportunidad laboral para familias vinculadas a la Residencia Socioeducativa Chicos de la Calle ... ofreciendo una publicación mensual que sirviera como ingreso digno a quienes atraviesan diferentes situaciones ligadas a la pobreza —desocupación, vulnerabilidad 
social, cirujeo, changas, limosnas-, y constituyendo un medio de comunicación que abordara esas temáticas y se propusiera sensibilizar la mirada de la opinión pública, Barriletes se consolidó como organización de la sociedad civil ... para luego avanzar en otros espacios y líneas de acción que atendieran la promoción integral de los jóvenes en lo social, educativo y cultural (Asociación Civil Barriletes, 2016).

Los vendedores de Revista Barriletes perciben un ingreso y se encuentran referenciados_ellos y sus problemáticas — en las páginas de los diferentes números.

\section{Los jóvenes de Entre Ríos}

\section{y su involucramiento en los medios comunitarios}

Si bien la participación en estos espacios no es privativa de jóvenes pobres urbanos, éstos asumen mayor protagonismo que jóvenes de otros sectores sociales así como también posiciones bien definidas en relación con esa condición. Pudimos caracterizar cuatro tipos de involucramiento, producidos no aisladamente sino que en la mayor parte de los casos interrelacionados unos con otros.

Por un lado, las y los jóvenes aparecen en el referente; esto es, forman parte de la temática del medio, generalmente a partir de la difusión de sus opiniones frente a diversos temas, experiencias, gustos, saberes. Aquí se destaca el propósito de contrarrestar representaciones que asocian la juventud y la pobreza a la peligrosidad dadas en los medios masivos de comunicación y con un fuerte anclaje en el imaginario colectivo. ${ }^{11}$ La propuesta de bajar la edad de imputabilidad de los delitos que gana fuerza en el debate acerca de la inseguridad del espacio público y mediático argentino y latinoamericano ${ }^{12}$ se deriva de esa asociación.

Por otro lado, algunos y algunas jóvenes forman parte de la distribución y difusión: participan de la venta o reparto de publicaciones

\footnotetext{
${ }^{11}$ Este vínculo es un tema abordado sustantivamente en los estudios sobre juventudes, podemos nombrar, por ejemplo: Margulis, 1998; Krauskopf, 2006; Míguez, 2010; Cappellino, 2011; Gentile, 2011; Kessler, 2012; Lerchundi y Bonvilliani, 2014; Schuttenberg y Ameghino, 2017. ${ }^{12}$ Cf. con documentación del Centro de Estudios Legales y Sociales, el Centro de Estudios en Política Criminal y Derechos Humanos, y la Coordinadora Contra la Represión Policial e Institucional.
} 
gráficas, principalmente, y en la propagación del medio y las actividades en torno a ellos. Señala una de las notas de la Revista Barriletes en su $16^{\circ}$ aniversario:

16 años de Remontar una oportunidad. Norma Zemboraim es una de las vendedoras más antiguas y valientes. Contra viento y marea sobrevive y construye un mundo más solidario y humano. Barriletes para mi es la puerta de la dignidad declaró Claudia Zapata otra de las vendedoras de la revista. Más de 15 familias lograron sostener este oficio de ofrecer un medio de comunicación independiente y autogestionado que produce y sueña con construir utopías (Asociación Civil Barriletes, 2017: 19).

Esta propuesta de participación se relaciona de modo directo con la idea de inclusión social que atraviesa las otras propuestas: ya que intenta para los y las jóvenes un ingreso — aunque precario e informalal mercado laboral. Aquí, el valor asignado al empleo responde a la interpretación del trabajo como un eje fuerte de la integración social, fuente de sentido para la vida personal, espacio para la participación ciudadana y motor del progreso material (Cepal, OIJ, 2003).

Un tercer modo de involucramiento es en la producción y realización comunicacional, esto es, como operadores de radio, reporteros barriales, conductores de programas, redactores y diseñadores gráficos, encuadernadores. Aquí se destaca la participación en talleres en los cuales niños y jóvenes se forman en diferentes áreas del periodismo y participan de programas y la producción de notas o ilustraciones, esto ocupa un lugar importante en la construcción de imaginarios e identidades juveniles. En general, en todas las experiencias reveladas este involucramiento se presenta motivado y articulado desde iniciativas pedagógicas como la de educación popular de Paulo Freire, la cual pone la comunicación y la educación en un terreno común atravesado por la cultura y, con ella, por la hegemonía, concebida como el proceso de permanente creación y recreación de los mecanismos de poder a través de recursos simbólicos (Brito Lorenzo, 2008).

Finalmente, se identifica la participación de jóvenes en la iniciativa, es decir, en la generación del proyecto comunicacional. Sin embargo, esta inserción asume una menor relevancia, puesto que en general estos 
proyectos de medios de comunicación se desprenden de diferentes formas organizativas preexistentes con protagonismo de referentes adultos.

En los diferentes casos, la participación de estos y estas jóvenes involucra la formación en oficios - fundamentalmente vinculados a la comunicación - o el aprendizaje de saberes de gestión, administración, entre otros; así como también la realización de tareas con retribución económica — como los casos de operadores radiales, que cumplen horas garantizando la programación de radios comunitarias, alternativas y populares, o el de los jóvenes distribuidores de revistas de calle-. Con esto, podemos decir que los medios de comunicación sostenidos por colectivos políticos y sociales incursionan en un doble propósito que articula la visibilización de problemáticas sociales que tocan a gran parte de este sector poblacional con la apertura de espacios laborales y la formación en oficios para ello. En general, desde un posicionamiento de oposición a las políticas sociales asistencialistas desde las cuales se ha descripto el periodo político del país de las últimas tres décadas. Esta doble empresa aparece referenciada como mecanismo de inclusión social para marginados y excluidos del mercado laboral y con inserciones precarias en el sistema educativo formal a la vez que como interpelación al Estado en tanto garantizador de derechos e inclusión social.

\section{Los medios y las juventudes según la mirada adulta}

Intentar aproximarnos a las experiencias de las juventudes implicó también identificar los discursos de adultos con quienes éstas interactúan. Entre ellos, pueden destacarse algunas ideas: a) referencias a las juventudes que involucran como "los chicos y jóvenes en riesgo social", "chicos de la calle" o "jóvenes generalmente destinatarios de políticas estatales asistencialistas o represivas"; b) la necesidad de visibilizar e interpelar a las diferentes jurisdicciones estatales en torno a las vulnerabilidades que sufren los jóvenes, a la vez que avanzar en acciones vinculadas a la inclusión social de las grandes porciones afectadas de este grupo poblacional. En palabras de uno de los referentes:

Nosotros veíamos cómo los vecinos, más que nada los pibes, padecían 
las consecuencias de las políticas de los 90. No pudimos mirar para otro lado, empezamos a preguntarnos qué necesitaban los pibes y las pibas del barrio: muchos no iban a la escuela ni tenían trabajo, pero tampoco iban al cine, ni al teatro, ni se reían mucho, en general. Y el Estado no estaba dispuesto a hacer nada con eso, menos después de la hecatombe de 2001. Así que dijimos: "bueno, lo tendremos que garantizar nosotros", y de paso serviría para mostrarle a los gobiernos lo que ellos no estaban garantizando (entrevista, 11 de diciembre de 2017).

Entre los adultos parece haber acuerdo en otra necesidad: la de que los y las jóvenes denuncien sus realidades sociales a través de prácticas mediáticas. Es decir, pongan en la escena pública sus condiciones de vida y participen de la pugna por la agenda mediática.

Que los nińos y los jóvenes están estigmatizados, que no son lo que los medios hegemónicos dicen que son, eso nosotros lo vemos todos los días. Tienen problemas, pero también tienen proyectos de futuro. Y eso hay que decirlo. La participación a veces cuesta, pero porque los pibes tienen miles de problemas. Cuando se enganchan a hacer una nota o salir en el micrófono, producen cosas hermosas (entrevista, 3 de octubre de 2017).

La idoneidad de las prácticas mediáticas parece no cuestionarse. "Hay que dar la batalla cultural, y la herramienta son los medios", remata el referente entrevistado.

Por otro lado, en general consideran que la inclusión es posible por medio de la garantización de un ingreso monetario periódico así como también a partir de la formación en oficios. Aquí se destacan los proyectos de operadores radiales y los vendedores de revistas que perciben ingresos por esas actividades como alternativas de ingreso al mercado laboral. Finalmente, concuerdan que el acceso a bienes culturales permite acompañar ese proceso de inclusión:

Los chicos también tienen que ir al cine, al teatro... porque son chicos. No tienen que vivir preocupados por lo terrible que es la vida que les tocó, como si fueran adultos. Nosotros acá trabajamos por el derecho 
a la cultura también. Tenemos talleres de murga, una biblioteca ambulante, cine debate, títeres, y un montón de cosas más (entrevista, 21 de octubre de 2017).

\section{Una aproximación a las experiencias juveniles}

Los relatos de las y los jóvenes participantes en general no remiten a condicionantes estructurales que las y los pongan en situación de marginalidad o exclusión social. Por el contrario, en varias ocasiones hablan de elecciones condenatorias en sus trayectorias vitales o cuestiones vinculadas al mérito. En palabras de Jésica: “a mí lo que me pasa es todo culpa mía. Yo no terminé la escuela, quién me va a dar trabajo a mí, si no sé nada". Axel sentencia: "Yo podría haber terminado en una zanja, como un amigo que ya no está. Pero por suerte me di cuenta y estoy tratando de salirme, la calle te confunde". La referencia a la calle es constante y suele aparecer como opuesta a la casa, a la escuela o al trabajo. Lo distintivo de las palabras de Axel es que en sus ratos libres hace rap, particularmente en la calle, junto con otros cinco amigos.

Los jóvenes se representan a sí mismos como discriminados y comentan ser tratados o mirados como "pibes chorros 13 " o "negros", principalmente los varones. Entre las mujeres, varias dicen ser discriminadas por el territorio al que pertenecen. También aparecen referencias a un estilo de vida juvenil que en general es "entendido mal" en el mundo adulto: "Es que la gorrita a los viejos no les gusta, hasta les molesta. Te miran mal". Esto parece contradecirse con la idea de "ser responsables de lo que les pasa"; sin embargo, se trata de representaciones que coexisten. Dice Brian en entrevista: "A nosotros nos vigila la policía, no podés salir sin el documento en el pantalón. ¡No te lo podés olvidar!, menos si pensás andar por el centro. Porque es así: te ven cara de chorro y te paran". Si bien se trata de jóvenes que participan de los medios comunitarios, cuando ellos refieren a sus inserciones, les quitan relevancia: "En realidad el Juani y la Juli hacen todo, ellos son los que se ponen por nosotros, los que se preocupan por los problemas que tenemos acá en el barrio, nosotros sólo les hacemos el aguante", dice Axel.

Por su parte, Ismael comenta: "A mí me gusta venir a la radio, cuando estoy al pedo vengo. Y me pongo a cebar mates o a pegar carteles...

${ }^{13}$ Expresión peyorativa que describe a jóvenes que delinquen. 
ahora estoy barnizando unas maderas que vamos a poner en el fondo para tapar la humedad... pero hablar en la radio no, ¡ni loco! No es lo mío. Yo quiero ser boxeador" (entrevistas, 19 de octubre de 2017).

Las y los jóvenes vendedores de revistas u operadores radiales no creen que esas actividades sean una "salida laboral". Más bien, remiten a su participación allí como "changa ${ }^{14}$ " para "hacerte unos pesos que después se te hacen humo en la mano". Y en general, en el caso de los vendedores, su frecuencia en esta actividad varía de acuerdo con otras "changas" que se les presentan. Las referencias a los medios en los que participan son las de "un lugar de encuentro", "para compartir con otros", "para pasarla bien y olvidarse de todo lo que me pasa”, entre otras similares. Dice Matías: "Que los que hablan al pedo de este lugar se laven la boca. Acá te sacan de la calle, te muestran que la vida es linda". Concluye Abigail: "Esto es mi segunda familia. Es así, somos como una familia, con todos los problemas que tiene una familia y con todas las cosas buenas".

\section{Algunas reflexiones e indagaciones finales}

A lo largo de estas páginas hemos podido identificar cuestiones estructurales vinculadas a procesos de marginación y exclusión social de las juventudes pobres urbanas, así como también las diferentes acciones que despliegan medios de comunicación insertos en organizaciones sociales en términos de inclusión de este grupo. Esto, a partir de un somero revelamiento en la provincia de Entre Ríos que nos permitió identificar prácticas y espacios y una serie de rasgos de diferentes modalidades de participación de las juventudes en el lugar.

En este sentido, se destacan dos ideas que parecieran inscribirse en dos grupos de actores involucrados de manera diferenciada: por un lado, la idea de inclusión social, emergente principalmente de los testimonios de adultos vinculados fuertemente a los colectivos que sostienen los medios de comunicación. Y por otro, la idea de "espacio de encuentro", de socialidad, del "estar juntos", mayormente sostenida por jóvenes. El Estado, a su vez, aparece referenciado por los primeros como el respon-

\footnotetext{
${ }_{14}$ Trabajo ocasional, generalmente en tareas menores, que permite la subsistencia mientras se busca otro de carácter fijo. Por ejemplo, cortar el pasto, hacer arreglos menores en inmuebles, limpiar casas, etcétera.
} 
sable "ausente" de los procesos de marginación y exclusión social.

En cambio, las juventudes refieren a sus condiciones de vida de manera más compleja, encontrándose aquí una tensión: entre vivenciarlas como consecuencia directa de sus acciones - haber dejado la escuela, no trabajar, pasarse tiempo con amigos en la calle- y sentir ser objeto de discriminación y estigmatización constante por condiciones de pobreza de las que sienten no poder salir por su propia cuenta.

La inclusión en espacios laborales y formativos es reconocida por los referentes adultos de las experiencias y por los y las jóvenes como precaria o insuficiente. Sin embargo, por los primeros es también es representada como una cuestión de "dignidad" y vinculada a proyectos de futuro. Los y las jóvenes, por su parte, la nombran como actividades transitorias.

Quedan, con esta contextualización de experiencias y primeras aproximaciones, nuevas preguntas. Particularmente, sugerimos $-\mathrm{y}$ pretendemos continuar indagando sobre ello- que estos espacios se constituyen como verdaderos espacios comunitarios de significación (Fasano, 1993) capaces de producir sentido en torno a deseos y proyectos de futuro de las juventudes así como tensiones con la mirada adulta de los referentes de los medios y con las estigmatizaciones propuestas por los discursos hegemónicos: joven peligroso, víctima o apático. Nos interesa seguir indagando en torno a la tensión que surge entre la percepción de las condiciones de vida propias de la pobreza y el hecho de vivenciarlas como consecuencia directa de sus acciones - haber dejado la escuela, no trabajar, pasarse tiempo con amigos en la calle-. Por otro lado, también profundizar en las diferencias acerca de lo que significan esos espacios comunitarios: inclusión social, proyecto de futuro, "un lugar donde podemos estar juntos". Finalmente, nos preguntamos si las prácticas mediáticas no son para estas y estos jóvenes los espacios privilegiados donde decir, donde poner en común lo que les ocurre, ¿existen otras prácticas de expresión en que sí lo hacen? ¿Qué sentidos les otorgan a ellas? 


\section{Bibliografía citada}

Alfaro, Rosa María, 2000, "Culturas populares y comunicación participativa: en la ruta de las redefiniciones”, Razón y palabra, núm. 18, s.p.

Altimir, Oscar y Beccaría, Luis, 1998, "Efectos de los cambios macroeconómicos y de las reformas sobre la pobreza urbana en Argentina”, en BID y CEPAL, Politica macroeconómica y pobreza en América Latina y el Caribe, Mundi-Prensa, Madrid. AMARC-ALER, Andrés Geerts, Claudia Villamayor y Víctor van Oeyen (coordinadores), 2004, La Práctica inspira. 32 experiencias que pueden inspirar en el desafío de fortalecer el movimiento de radio popular y comunitaria del continente, AMARC-ALER, Quito.

Asociación Argentina de Teledifusoras Pyme y Comunitarias, Aateco, s.f., "Quiénes somos Aateco", documento de difusión de la organización, Argentina.

Asociación Civil Barriletes, 2016, "Remontando una oportunidad", Revista Barriletes, núm. 186, pp. 6-7.

Asociación Civil Barriletes, 2017, Revista Barriletes, núm. 188, pp. 18-20. Brito Lorenzo, Zaylín, 2008, Educación popular, cultura e identidad desde la perspectiva de Paulo Freire, Clacso, [en línea] disponible en http://biblioteca. clacso. edu. ar/ar/libros/campus/ freire/06Brito. Pdf [fecha de consulta: junio de 2018].

Cabral, María Cristina, 2004, “Tomá la voz, dámela a mí. Experiencia de Radio Encuentro en el trabajo con jóvenes”, disponible en http://www.radioencuentro.org.ar/cristinaponenciaradio.doc

Cabral, María del Carmen y Diego Jaime, 2009, "Jóvenes y radios comunitarias. La experiencia de FARCO”, ponencia en el Primer Encuentro sobre Juventud, Medios de Comunicación e Industrias culturales, Jumic, Universidad Nacional de La Plata, disponible en https://perio.unlp.edu.ar/observatoriodejovenes/ taxonomy/term/13 
Cappellino, María Elena, 2011, “Código de Faltas: un análisis de las políticas de tolerancia cero en los sectores vulnerables de Córdoba”, en L. Crisafulli y I. León Barreto (coordinadores), ¿iCuánta Falta!? Código de Faltas, Control Social y Derechos Humanos, Ed. INECIP, Córdoba, Argentina, pp. 65-80.

Chaves, Mariana, 2005, "Juventud negada y negativizada: representaciones y formaciones discursivas vigentes en la Argentina contemporánea", Última década, vol. 23, núm. 13, pp. 9-32.

Chaves, Mariana, 2017, "Jóvenes entre el centro y la periferia de la ciudad, del Estado y de la academia”, Ciudadanías. Revista de Políticas Sociales Urbanas, núm 1, pp. 71-96.

Comisión Económica para América Latina y el Caribe y Organización Iberoamericana de Juventud, Cepal y OIJ, 2003, Juventud e inclusión social en Iberoamérica, Cepal, Santiago de Chile.

Cubides Martínez, Juliana, 2016, "Movimientos Juveniles contemporáneos en América Latina. Juventud y política en la encrucijada neoliberal", en Fernanda Espíndola Ferrer (coordinadora), Jóvenes en movimientos: experiencias y sentidos de las movilizaciones en la América Latina contemporánea, Clacso, Ciudad Autónoma de Buenos Aires, Argentina.

Dirección General de Estadística y Censo, 2010, Provincia de Entre Ríos según área de gobierno local. Población por sexo, [en línea] disponible en https://www.entrerios.gov.ar/dgec/ [fecha de consulta: 25 de febrero de 2018].

Fasano, Patricia, 1993, Comunicación popular: Espacios comunitarios de significación de los sectores populares urbanos, tesis de licenciatura, Universidad Nacional de Entre Ríos, Argentina.

Fasano, Patricia, 2001, “El 'Ciclón’ de Anacleto Medina Sur. —Sobre la construcción de la identidad en sectores de pobreza urbana-”, Ciencia, Docencia y Tecnología, núm. 22, pp. 137-165.

Fasano, Patricia, 2015, "La investigación en comunicación comunitaria y popular: el uso de la etnografía como enfoque", AVATARES de la comunicación y la cultura, núm. 10, [en línea] disponible en http://ppct.caicyt.gov.ar/index.php/avatares/issue/view/538 [fecha de consulta: octubre de 2017]. 
Feijoó, María del Carmen, 2015, "Los ni-ni: una visión mitológica de los jóvenes latinoamericanos”, Voces en el Fénix, núm. 51, pp. 22-31.

Fernández, Ana María y Mercedes López, 2005, "Vulnerabilización de los jóvenes en Argentina: política y subjetividad", Nómadas, núm. 23, pp. 132-139.

Festa, Regina y otros, 1986, Comunicación popular y alternativa, Ediciones Paulinas, Buenos Aires.

Gentile, María Florencia, 2011, "Los procedimientos discursivos para la construcción mediática de la figura del joven pobre y delincuente. El 'Caso Jonathan'”, Última Década, núm. 34.

Gerbaldo, Judith, 2010, "Comunicación comunitaria/popular y participación ciudadana en el actual escenario comunicacional”, AA.VV., Todas las voces Todos, Farco, Buenos Aires.

Instituto Nacional de Estadística y Censos de la República Argentina, Indec, 2014, "Encuesta Nacional de Jóvenes (ENJ 2014)", disponible en http:/www.indec.gob.ar/ftp/cuadros/poblacion/ resultados_enj_2014.pdf [fecha de consulta: 1 de marzo de 2018].

Instituto Nacional de Estadística y Censos de la República Argentina, Indec, 2016, “Índices de pobreza segundo semestre 2016", [en línea] disponible en http://www.indec.gob.ar [fecha de consulta: 1 de marzo de 2018].

Instituto Nacional de Estadística y Censos de la República Argentina, Indec, 2017, "Incidencia de la pobreza y la indigencia en 31 aglomerados urbanos. Primer semestre de 2017”, [en línea] disponible en https://www.indec.gob.ar/uploads/informesdeprensa/eph_pobreza_01_17.pdf [fecha de consulta: 3 de abril de 2018].

Kaplún, Mario, 1985, El comunicador popular, Humanitas, Buenos Aires. Kejval, Larisa, 2009, Truchas: los proyectos politico-culturales de las radios comunitarias, alternativas y populares argentinas, Prometeo Libros, Buenos Aires.

Kejval, Larisa, 2013, Significaciones en torno a las radios comunitarias, populares y alternativas argentinas, tesis de maestría, Universidad 
de Buenos Aires, Buenos Aires.

Kessler, Gabriel, 2012, "Las consecuencias de la estigmatización territorial. Reflexiones a partir de un caso particular", Espacios en Blanco. Revista de Educación, núm. 22, pp. 165-198, Universidad Nacional del Centro de la Provincia de Buenos Aires. Buenos Aires, Argentina.

Kessler, Gabriel y Mariana Di Virgilio, 2008, "La nueva pobreza urbana: dinámica global, regional y argentina en las últimas dos décadas", Revista de la CEPAL, núm. 95, pp. 31-50.

Krauskopf, Dina, 2006, Juventudes en América Latina y el Caribe: dimensiones sociales, subjetividades y estrategias de vida. Asociándose con la Juventud para construir el futuro, Fundación Kellog, Editoral Peirópolis, Sao Paulo.

Krohling Perusso, Carolina, 1998, "Comunicação nos movimentos populares. A participação na construçáo da cidadania", Editora Vozes, Petrópolis (RJ).

Krohling Perusso, Carolina, 2008, "Conceitos de comunicação popular, alternativa e comunitária revisitados”, Reelaboraçóes no setor. Palabra Clave, vol. 2, núm. 11, pp. 367-379.

Lamas, Ernesto y Hugo Lewin, 1995, “Aproximación a las radios de nuevo tipo: tradición y escenarios actuales”, Causas y azares, vol. 2, núm. 2, pp. 70-86.

Lattes, Alfredo, 1995, "Urbanización, Crecimiento Urbano y Migraciones en América Latina”, Notas de Población, núm. 62, pp. 211-260.

Lerchundi, Mariana y Andrea Bonvillani, 2014, "Jóvenes y Código de Faltas. Una 'experiencia' de detención”, Justicia Juris, vol. 1, núm. 10, pp. 43-52.

Ley Nacional de Radiodifusión $N^{\circ}$ 22.285, [en línea] disponible en http://www.uba.ar/radiodifusion/download/ley22285.pdf [fecha de consulta: julio de 2018].

Ley Nacional de Servicios de Comunicación Audiovisual $N^{\circ}$ 26522, [en línea] disponible en http://servicios.infoleg.gob.ar/ infolegInternet/anexos/155000-159999/158649/norma.htm [fecha de consulta: julio de 2018]. 
Ley Nacional de Servicios de Comunicación Audiovisual $N^{\circ}$ 26522, Modificaciones a la Ley $\mathrm{N}^{\circ}$ 26522, Decreto $\mathrm{N}^{\circ}$ 267/2015, [en línea] disponible en http://servicios.infoleg.gob.ar/infolegInternet/ anexos/255000-259999/257461/norma.htm [fecha de consulta: junio de 2018].

Margulis, Mario, 1998, "La discriminación en la discursividad social", Margulis, M y M Urresti, (compiladores), La segregación negada. Cultura y discriminación social, Ed. Biblos, Buenos Aires, pp. 17-36.

Mata, María Cristina, 1993, “¿ Radio popular o comunitaria?”, Chasqui. Revista Latinoamericana de Comunicación, núm. 47, pp. 57-59. Mata, María Cristina, 1998, "Jóvenes y radios populares: ¿nuevas búsquedas o productos del mercado?", Causas y Azares, núm. 7, pp. 111-120, Buenos Aires, Argentina.

Mata, María Cristina, 2002, “Comunicación, ciudadanía y poder: pistas para pensar su articulación”, Diálogos de la Comunicación, núm. 64, FELAFACS, Lima, [en línea] disponible en http://dialogosfelafacs.net/edicion-64/ [fecha de consulta: marzo de 2018].

Mata, María Cristina, 2006, "Comunicación y ciudadanía. Problemas teórico-políticos de su articulación”, Fronteiras-estudos midiáticos, vol. 1, núm. 8, pp. 5-15.

Mc. Bride, Sean, 1980, Voces Múltiples, Un Solo Mundo, Fondo de Cultura Económica, México.

Merklen, Denis, 2005, Pobres ciudadanos. Las clases populares en la era democrática (Argentina 1983-2003), Gola, Buenos Aires.

Mesa Suárez, Paula. 2014, RNMA La conformación de una red de medios alternativos en Argentina, Tesis de Grado, Facultad de Ciencias Sociales, Universidad de Buenos Aires, [en línea] disponible en http://comunicacion.sociales.uba.ar/wp-content/uploads/ sites/16/2013/02/TESINA_Paula_Mesa_Suarez.pdf [fecha de consulta: julio de 2018].

Míguez, Daniel, 2010, Los pibes chorros. Estigma y marginalización, Editorial Capital Intelectual, Buenos Aires.

Mingo de Bevilacqua, Graciela, Elisa Sarrot, Miguel Bitar, Alicia González Alarcón, Mirta Soijet, Cesar Sione y Gabriela Romero, 
2006, "Dimensiones de la pobreza en Paraná y Concordia: Un estudio comparativo", Ciencia, docencia y tecnología, núm. 33, pp. 67-110.

Observatorio de la Deuda Social Argentina, 2017, "Pobreza y desigualdad por ingresos en la Argentina urbana 2010-2017”, disponible en http://uca.edu.ar/es/observatorio-de-la-deudasocial-argentina/barometro-de-la-deuda-social-argentina/ informes-tematicos-de-la-deuda-social-argentina

Red Nacional de Medios Alternativos, RNMA, 2009, "La ley de servicios de comunicación audiovisual", documento de difusión de la organización, Argentina.

Saintout, Florencia, 2013, Jóvenes en Argentina. Contra el discurso mediático. Desde una epistemología de la esperanza, Universidad Nacional de Quilmes, Bernal.

Schuttenberg Mauricio y Mariano Ameghino, 2017, “La (In)seguridad antes de la (in)seguridad. Análisis de las tapas del diario Clarín 1983-2004”, en G. Irrazabal, N. Dallorso, N. Costa y C. Cesaroni (directores), Gestión de la inseguridad, violencias $y$ sistema penal, Tren en Movimiento Ediciones, Buenos Aires.

Svampa, Maristella, 2005, La sociedad excluyente: la Argentina bajo el signo del neoliberalismo, Taurus, Buenos Aires.

Vega Cantor, Renán, 2009, "Crisis civilizatoria”, Revista Herramienta, núm. 42, [en línea] disponible en: https://www.herramienta. com.ar/ [fecha de consulta: marzo de 2018].

Vommaro, Pablo, 2012, "Los procesos de subjetivación y la construcción territorial: un acercamiento desde experiencias de organizaciones sociales en Buenos Aires", en Subjetividades politicas, Clacso, Buenos Aires.

Vommaro, Pablo, 2015, Juventudes y politicas en la Argentina y en América Latina: tendencias, conflictos y desafios, Grupo Editor Universitario, Ciudad Autónoma de Buenos Aires, Argentina. 
Sitios web referenciados

Centro de Estudios en Política Criminal y Derechos Humanos: http://cepoc-cepoc.blogspot.com/

Centro de Estudios Legales y Sociales:

https://www.cels.org.ar/web/

Coordinadora Contra la Represión Policial e Institucional:

http://www.correpi.lahaine.org/

Foro Argentino de Radios Comunitarias, Farco:

http://www.farco.org.ar/

Indymedia Argentina:

https://argentina.indymedia.org/

Red Nacional de Medios Alternativos, RNMA:

https://rnma.org.ar/ 